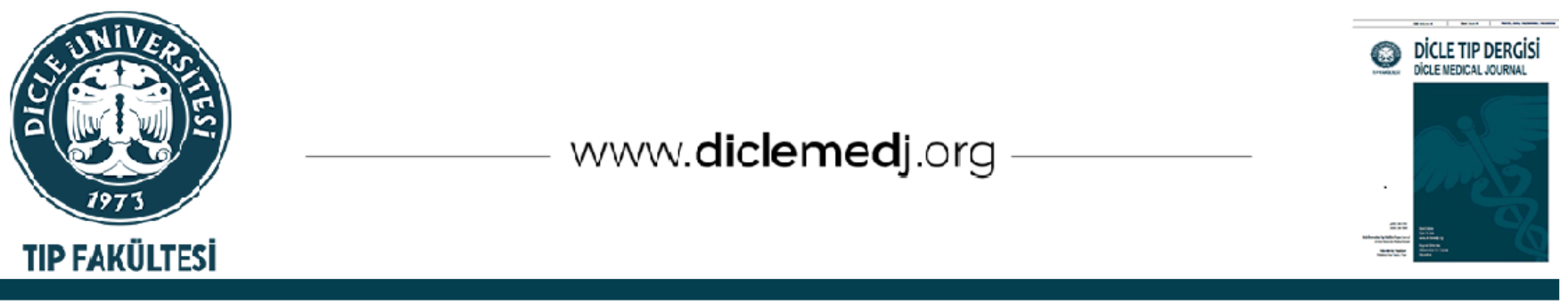

\title{
ST Segment Yükselmesiz Akut Koroner Sendromlu Yaşlı Hastalarda Girişimsel Tedavi ile Konservatif Tedavinin Altı Aylık Dönemde Mortalite Üzerine Etkilerinin Karşılaştırılması
}

\author{
Ferhat Işık ${ }^{D}$ 1, Ümit İnci ${ }^{D}{ }_{1}$, Abdurrahman Akyüz ${ }^{i}{ }_{1}$, Habib Çil ${ }^{i}{ }_{2}$ \\ 1 Sağlık Bilimleri Üniversitesi, Gazi Yaşargil Eğitim ve Araştırma Hastanesi, Kardiyoloji ABD. Diyarbakır, Türkiye \\ 2 Avrasya Hospital, Kardiyoloji ABD. Zeytinburnu-İstanbul, Türkiye
}

Geliş: 09.01.2021; Revizyon: 02.06.2021; Kabul Tarihi: 14.06.2021

Öz

Giriş: Çalışmamızın amacı, ST segment yükselmesiz akut koroner sendrom (NSTEAKS) tanısı ile hastaneye yatırılan yaşlı (65 yaş ve üstü) hastalarda girişimsel tedavi ve konservatif tedavi gruplarının 6 aylık dönemde mortalitelerini karşılaştırmaktır.

Yöntemler: Çalışmamızda NSTEAKS tanısı ile hastaneye yatırılan 65 yaş ve üstü ardışık 300 hasta retrospektif olarak incelendi. Hastane kayıt sisteminden tüm hastaların verilerine ulaşıldı. Hastalar girişimsel tedavi alanlar ve konservatif tedavi verilenler olarak iki gruba ayrıldı. Ayrıca 6 aylık süreçte ölen hastalar ve yaşayan hastalar, iki grup olarak karşılaştırıldı.

Bulgular: Çalışmaya alınan hastaların yaş ortalaması $74.72 \pm 6.42$ olup 157'si (\%52) kadındı. Girişimsel ve konservatif tedavi grubunun yaş ortalamaları benzerdi $(73.67 \pm 5.92$ vs $75.77 \pm 6.78, p=0.05)$. Çalışma popülasyonunda 6 aylık dönemde mortalite oranı \%13,6 idi. Girişimsel tedavi gurubunda mortalite anlamlı olarak daha düşüktü $(\% 8,6$ vs \%18,6, $\mathrm{p}=0.018$ ). Çalışmamızda, çok değişkenli lojistik regresyon analizi ile 6 aylık mortalitede bazı öngördürücüler tespit ettik. Bunlar; çok yüksek CRUSADE kanama riski [Odds oranı (OR): 1.911, güven aralığı (GA) \%95 (1.964 - 28.186), p= 0.030)], konservatif tedavi stratejisinin benimsenmesi [OR: 1.127, GA \%95 (0.131 - 0.799), p=0.014)] ve kardiyak biyobelirteçlerinin (troponin) pozitifliğiydi [OR: 1.837, GA \%95 (1.928 - 25.391), p=0.030)].

Sonuç: Yaşlı NSTEAKS hastalarında 6 aylık mortaliteyi öngörmede konservatif tedavi stratejisi bağımsız bir prediktördür. Başka ifade ile girişimsel tedavi yapılması, yaşlı hastalarda mortaliteyi azaltmıştır. Bu sonuçlar yaşlı hastaların da kapsamlı bir değerlendirmeden sonra girişimsel tedaviden fayda görebileceğini göstermektedir.

Anahtar kelimeler: Yaşll; girişimsel; konservatif; mortalite

DOI: $10.5798 /$ dicletip.988065

Correspondence / Yazıșma Adresi: Ferhat Işık, Diclekent Mahallesi, 616.sokak, Boğaziçi Evleri A blok No: 4, Kayapınar, Diyarbakır 21070, Türkiye e-mail: frht_0316@hotmail.com 


\title{
Comparison of the Effects of Interventional Treatment and Conservative Treatment on Mortality in Six Months in Elderly Patients with Non-ST Segment Elevation Acute Coronary Syndrome
}

\begin{abstract}
Introduction: We aimed to compare 6 month-mortality of elderly patients ( $\geq 65$ years of age) presented with non-ST segment elevation acute coronary syndrome (NSTEACS) treated with interventional methods and that of patients treated by conservative approach.

Methods: A total of 300 consecutive patients aged 65 and older presented NSTEACS were enrolled to this retrospectively designed study. Data of all patients were reached from hospital records. Patients were divided into two groups as interventional and conservative treatment. İn addition patients who died during the 6-month period and who survived were compared in two groups.

Results: Mean age of the study population was $74.72 \pm 6.42$ years, and 157 (52\%) of them were female. The average age of interventional and conservative treatment group was similar (73.67 \pm 5.92 vs $75.77 \pm 6.78, p=0.05)$. Six monthmortality of study population was $13.6 \%$, while this was lower in patients treated by interventional approach (8.6 \% vs. $18.6 \%, \mathrm{p}=0.018$ ). The predictors of 6 month-mortality were found as high CRUSADE bleeding risk [OR (Odds Ratio) $: 1.911,95 \%$ confidence interval (CI) (1.964 - 28.186), $\mathrm{p}=0.030)]$, conservative treatment [OR :1.127, 95\% CI (0.131 0.799), p:0.014)] and troponin positivity [OR :1.837, 95\% CI (1.928 - 25.391), p=0.030)].

Conclusion: Conservative treatment is an independent predictor for predicting 6-month mortality in elderly patients with NSTEACS. In other words, interventional treatment has reduced mortality in elderly patients. These results show that elderly patients may also benefit from interventional treatment after a comprehensive evaluation.
\end{abstract}

Keyword: Elderly; interventional; conservative; mortality

\section{Giriş}

Yaşlı tanımı için toplumlar arasında farklılık olmakla birlikte Dünya Sağlık Örgütüne göre 65 yaş ve üzeri popülasyon, yaşlı olarak tanımlanır ${ }^{1}$. Yaşlanma süreci veya ileri yaş, kardiyovasküler hastalıklar için en önemli risk faktörlerinden biridir. Her yıl kardiyovasküler hastalıklara bağlı ölümlerin yarısından fazlasını 70 yaş üzerindeki kişiler oluşturmaktadır². Akut koroner sendrom (AKS) tanısı ile hastaneye yatışların yaklaşık \%60'ını 65 yaş üstü hastalar oluşturur ve AKS ile ilişkili ölümlerin yaklaşık \%85'i bu yaş grubunda görülür ${ }^{3}$. İleri yaşın, AKS sonrasında kötü prognoz için güçlü bir gösterge olduğu bilinmektedir. Yaşlı hastalarda ST elevasyonlu miyokart enfarktüsü (STEMI) kliniğinden ziyade NSTEAKS tablosu görülür. Kayıtlarda yüksek oranda yaşlı hasta bulunmasına rağmen, 75 yaşından büyük hastalar ST segment NSTEAKS çalışmalarındaki tüm hastaların \%20'sinden azını temsil etmektedir ${ }^{4}$. Çalışmalara alınan hastalar daha düşük kardiyovasküler risk faktörleri, daha az komorbiditeleri, daha iyi hemodinamik ve renal fonksiyonları olan hastalardan seçilmiştir. $\mathrm{Bu}$ durumda klinik çalışmalardaki bulguların rutin klinik pratikte rastlanılan yaşlı hastalara uygulanabilme durumu sorgulanmalıdır. Yaşlı AKS hastalarının nasıl tedavi edilmesi gerektiği konusundaki bilgiler sınırlıdır ${ }^{5,6}$. Çalışmamızda NSTEAKS tanısıyla hastaneye yatırılan 65 yaş ve üzerindeki hastalarda girişimsel tedavi ile konservatif tedavinin 6 aylık dönemde mortalite üzerine etkilerini inceledik.

\section{YÖNTEMLER}

Çalışmamızda Ocak 2011- Mayıs 2013 tarihleri arasında Dicle Üniversitesi Hastanesi Kardiyoloji kliniğinde yatan NSTEAKS tanılı 65 yaş ve üstü ardışık 396 hasta retrospektif olarak incelendi. Hasta dosya kayıtları ve hastane sistemi üzerinden hastaların demografik bilgilerine, laboratuvar parametrelerine, elektrokardiyografi (EKG) ve transtorasik ekokardiyografi ile yapılan sol ventrikül ejeksiyon fraksiyonu (EF) kayıtlarına ulaşıldı. Dışlama kriterleri, son dönem böbrek yetmezliği, malignite, akut serebrovasküler olay, 
akut pulmoner emboli, aktif enfeksiyon varlığı (sepsis..vb), kanama diyatezi olarak belirlendi. Kayıtlı herhangi bir iletişim bilgisi olmayanlar, hastane verileri eksik olanlar ve dişlama kriterleri uyan hastaların ekartasyonu sonrasında 300 hasta girişimsel ve konservatif tedavi olarak iki gruba ayrıldı (Şekil 1). Her hastanın GRACE (Global Registry of Acute Coronary Events-Akut Koroner Olayların Global Kayıtları) risk skoru ve CRUSADE (Can rapid risk stratification Unstable Angina-Kararsız anjina hastalarında hızlı risk sinıflandırması) kanama skoru hesaplandı. MDRD (Modification of Renal Disease) ile GFR (Glomerüler Filtration Rate) değerleri hesapland. Her iki grupta hastalar kardiyak enzim yüksekliğine göre Anstabil Anjina Pektoris (UAP) ve ST elevasyonsuz miyokart enfarktüsü (NSTEMI) olarak belirlendi. Altıncı ayın sonunda tüm hastalara, kayıtlardaki bilgilerinden ulaşıldı ve sağkalımları hakkında bilgi alındı. Hastalar, ölüm ve sağkalım gruplarına ayrıldı. Çalışmamız için gerekli onay, hastanemiz etik kurulu komisyonundan alındı (22/01/2014 tarih ve sayı no:96).

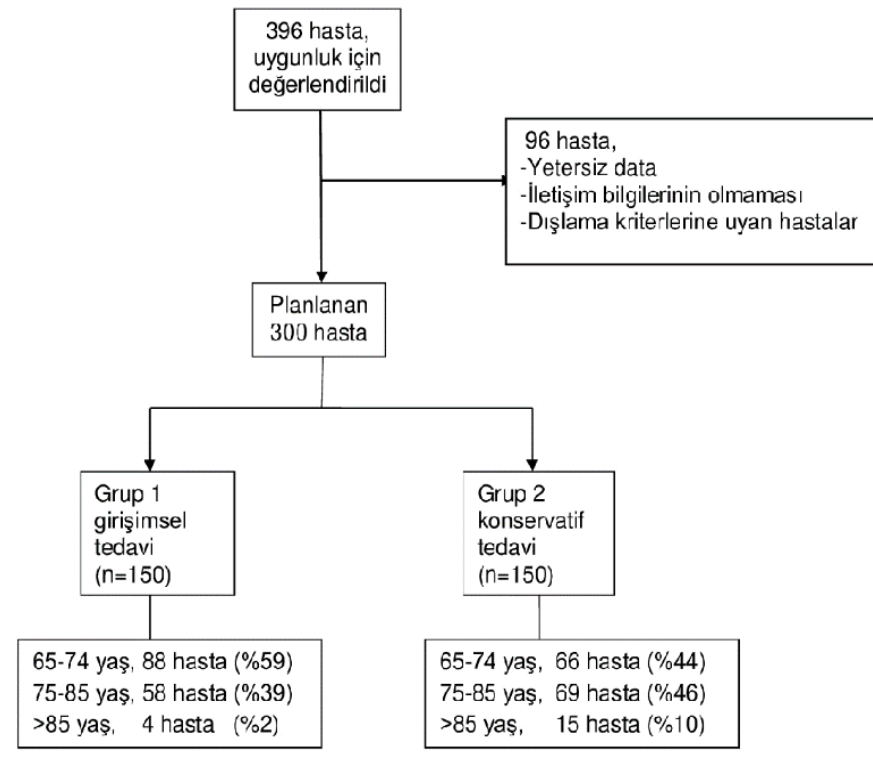

Şekil 1: Hasta seçiminin akış şeması ve yaş grubu dağılımları

\section{İstatistiksel Analiz}

Verilerin analizi SPSS (Statistical Packagefor Social Sciencefor Windows) -16 paket programı kullanılarak yapıldı. Sürekli değişkenler ortalama \pm standart sapma (SD) olarak verildi. Kategorik değişkenler yüzde (\%) olarak ifade edildi. Kategorik değişkenlerin karşılaştırılmasında Kikare Fischer Extact testi kullanlıldı. Bağımsız değişkenler analizinde Independent sample test kullanıldı. Çok değişkenli analizde değişkenlerin ilişkisi multivariate lojistik regresyon analizi ile araştırıldı. Elde edilen verilerin istatistiksel anlamlılık düzeyi "p" değeri ile yorumlandı. p< 0.05 değerleri istatistiksel olarak anlamlı kabul edildi.

\section{BULGULAR}

Çalışmamıza ardışık toplam 300 hasta alındı. Bu hastalar; girişimsel tedavi yapllanlar ve konservatif tedavi alanlar diye iki gruba ayrıldı (Tablo I). Tüm hastaların yaş ortalaması $74.72 \pm$ 6.42 olup \%52'si kadındı. Girişimsel tedavi yapılanlar ile konservatif tedavi alanların yaş ortalaması benzerdi $(73.67 \pm 5.92$ vs $75.77 \pm 6.87$, $\mathrm{p}=0.05)$. 65-74 yaş arasında 154 hasta (\%51), 7585 yaş arasında 127 hasta (\%42), 85 yaş ve üstünde 19 hasta (\%7) bulunmaktaydı. Yaş ilerledikçe girișimsel tedavi stratejisi daha az uygulanmaktaydı (65-74 yaş için \%57, 75-85 yaş için \%46, >85 yaş için \%21). Girişimsel tedavi ve konservatif tedavi gurupları arasında; GRACE skoru, EF değeri, bilinen koroner arter hastalığ (KAH) öyküsü varlığl, diyabet varlığl, kan basıncl, kalp hızı, troponin (+) hasta sayısı, kanama oranları, hastane içi ölüm ve 3 . aydaki ölüm oranları açısından fark saptanmadı. Girişimsel tedavi grubunda; hipertansiyon, sigara kullanımı, başvuru hematokrit değeri, kadın cinsiyet oranı ve GFR değeri daha yüksekti. Konservatif tedavi kolunda; troponin değeri, başvuru kreatinin değeri, nötrofil/lenfosit oranı (NLR), MPV (mean platelet volume), CRUSADE kanama skoru, 6 aylık mortalite daha yüksekti. Altı aylık dönemde 300 hastanın 10 tanesi hastane içi olmak üzere 41'i öldü $(\% 13,6)$. Hastane içi mortalite oranı iki grupta benzer bulundu ( $\% 2,6$ vs $\% 4,0, p=0.212)$. Altı aylık mortalite ise girişimsel tedavi grubunda konservatif tedavi grubuna göre anlamlı olarak daha azdı (\%8,6 vs \%18,6, p= 0.018) (Şekil 2). 
Tablo I: Hastaların demografik özellikleri, klinik ve laboratuvar parametreleri

\begin{tabular}{|c|c|c|c|}
\hline & $\begin{array}{l}\text { Girișimsel } \\
(n=150)\end{array}$ & $\begin{array}{c}\text { Konservatif } \\
(n=150)\end{array}$ & p değeri \\
\hline Yaş, yll & $73.67 \pm 5.92$ & $75.77 \pm 6.78$ & 0.050 \\
\hline \multicolumn{4}{|l|}{ Yaş, grup } \\
\hline $65-74, \mathrm{n}(\%)$ & $88(59)$ & $66(44)$ & 0.050 \\
\hline 75-85, n(\%) & $58(39)$ & $69(46)$ & 0.040 \\
\hline$>85, \mathrm{n}(\%)$ & $4(2)$ & $15(10)$ & 0.020 \\
\hline Hipertansiyon, n(\%) & $115(76)$ & $92(61)$ & 0.006 \\
\hline Kadın cinsiyet, n(\%) & $88(58)$ & $69(46)$ & 0.037 \\
\hline Diyabetes mellitus, n(\%) & $58(38)$ & $44(29)$ & 0.113 \\
\hline Sigara, n(\%) & $44(29)$ & $62(41)$ & 0.040 \\
\hline Bilinen KAH, n(\%) & $61(40)$ & $65(43)$ & 0.908 \\
\hline CABG öyküsü, n(\%) & $19(13)$ & $21(14)$ & 0.865 \\
\hline PCI öyküsü, n(\%) & $28(19)$ & $26(17)$ & 0.440 \\
\hline Ejeksiyon fraksiyonu, \% & $49.1 \pm 10.8$ & $46.8 \pm 12.0$ & 0.110 \\
\hline \begin{tabular}{|lll} 
Sistolik & kan & basıncl, \\
mmHg & & \\
\end{tabular} & $140.0 \pm 23.1$ & $134.3 \pm 26.6$ & 0.640 \\
\hline Kalp hızı, atım/dk & $83.33 \pm 19.4$ & $86.45 \pm 20.9$ & 0.180 \\
\hline Troponin değeri, ng/ml & $6.88 \pm 14.15$ & $9.22 \pm 20.2$ & 0.011 \\
\hline $\begin{array}{l}\text { Troponin pozitif hasta, } \\
\mathrm{n}(\%)\end{array}$ & $104(69)$ & $92(61)$ & 0.182 \\
\hline Başvuru kreatinin, mg/dl & $0.95 \pm 0.43$ & $1.16 \pm 0.52$ & 0.001 \\
\hline MPV & $8.33 \pm 1.08$ & $8.67 \pm 1.57$ & 0.034 \\
\hline NLR & $4.74 \pm 5.92$ & $6.75 \pm 8.73$ & 0.025 \\
\hline Başvuru hematokrit, \% & $38.13 \pm 4.0$ & $36.8 \pm 6.0$ & 0.042 \\
\hline MDRD, ml/dk & $78.0 \pm 21.0$ & $74.05 \pm 25.1$ & 0.040 \\
\hline GRACE skor & $145.47 \pm 28.1$ & $\begin{array}{c}147.17 \pm \\
29.71\end{array}$ & 0.608 \\
\hline CRUSADE skor & $33.73 \pm 13.2$ & $37.21 \pm 14.7$ & 0.030 \\
\hline Kanama, n(\%) & $8(5)$ & $8(5)$ & 0.990 \\
\hline Hastane içi ölüm, n(\%) & $4(2.6)$ & $6(4.0)$ & 0.212 \\
\hline 3.ay ölüm, n(\%) & $11(7.3)$ & $17(11.3)$ & 0.088 \\
\hline 6 aylık ölüm, n(\%) & $13(8.6)$ & $28(18.6)$ & 0.018 \\
\hline \multicolumn{4}{|c|}{$\begin{array}{l}\text { Sayısal değişkenler ortalama } \pm \text { standart sapma olarak, kategorik } \\
\text { değisskenler yüzdelik olarak verildi. CABG: Koroner arter bypass grefti, } \\
\text { CRUSADE: Can rapid risk stratification unstable angina-Kararsız anjina } \\
\text { hastalarında hızlı risk sinıflandırması, GRACE: Global Registry of Acute } \\
\text { Coronary Events-Akut Koroner Olayların Global Kayıtları, KAH: Koroner } \\
\text { arter hastalığı, MDRD: Modification of Renal Disease, MPV: Mean platelet } \\
\text { volume, NLR: Neutrophil/lymphocyte ratio, NSTEMI: Non ST elevasyonlu } \\
\text { miyokart enfarktüsü, PCI: Percutan coronay intervention }\end{array}$} \\
\hline
\end{tabular}

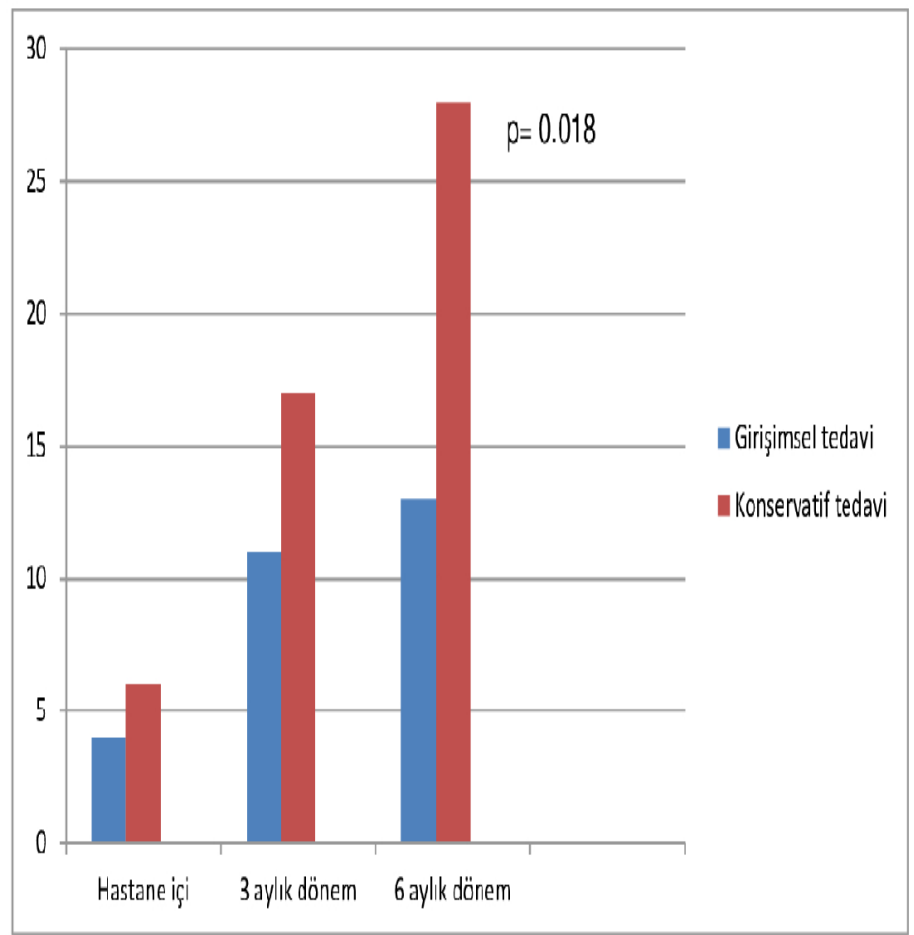

Şekil 2: Girişimsel ve konservatif tedavi gruplarında zamana göre mortalite

Altı ay sonunda ölen 41 hastanın yaş gruplarına göre dağlımı şu şekilde gerçekleşti; 65-74 yaş arasında 14 hasta (\%34), 75-85 yaş grubunda 24 hasta (\%59), 85 yaşından büyük olan grupta ise 3 hastaydı (\%7). Yaş ortalamasına göre baktığımızda, ölen hastaların yaş ortalaması, yaşayan hasta grubuna göre daha büyüktü $(76.66 \pm 5.39$ vs $74.41 \pm 6.60, p=0.020)$. Ölen hasta grubunda ayrica; troponin $(+)$ hasta sayısı, troponin değeri, kanama sıklığı, geliş kreatinini, GRACE ve CRUSADE risk skoru sağkalım grubundan anlamlı olarak daha fazlaydı. Girişimsel tedavi stratejisinin ölüm grubuna göre [13 hasta (\%32)] sağkalım grubunda [137 hasta (\%53)] daha fazla uygulandığı görüldü $(\mathrm{p}=0.018)$ (Tablo II). 
Tablo II: Ölüm ve sağkalım gruplarında demografik, ekokardiyografik, laboratuvar parametrelerinin ve risk skorlarının karşılaştırılması

\begin{tabular}{|c|c|c|c|}
\hline & Ölüm(n=41) & Sağkalım(n=259) & p değeri \\
\hline Yaş, yıl & $76.66 \pm 5.39$ & $74.41 \pm 6.60$ & 0.020 \\
\hline \multicolumn{4}{|l|}{ Yaş, grup } \\
\hline $65-74, \mathrm{n}(\%)$ & $14(34)$ & $140(54)$ & 0.056 \\
\hline $75-85, n(\%)$ & $24(59)$ & $103(40)$ & 0.550 \\
\hline$>85, \mathrm{n}(\%)$ & $3(7)$ & $16(6)$ & 0.410 \\
\hline Kadın cinsiyet, $\mathrm{n}(\%)$ & $20(49)$ & $137(53)$ & 0.737 \\
\hline $\begin{array}{l}\text { Diyabetes mellitus, } \\
\mathrm{n}(\%)\end{array}$ & $16(39)$ & $86(33)$ & 0.481 \\
\hline Hipertansiyon, n(\%) & $25(61)$ & $182(70)$ & 0.275 \\
\hline KAH öyküsü, n(\%) & $17(41)$ & $109(42)$ & 1.00 \\
\hline CABG öyküsü, n(\%) & $7(17)$ & $33(13)$ & 0.459 \\
\hline PCl öyküsü, n(\%) & $3(7)$ & $51(19)$ & 0.770 \\
\hline Sigara, n(\%) & $17(41)$ & $89(34)$ & 0.384 \\
\hline $\begin{array}{l}\begin{array}{l}\text { Troponin } \\
n(\%)\end{array} \\
\text { (+) hasta, }\end{array}$ & $37(90)$ & $159(61)$ & $<0.001$ \\
\hline Troponin değeri, ng/ml & $19.20 \pm 30.9$ & $6.29 \pm 13.5$ & 0.012 \\
\hline Kalp hızı, atım/dk & $84.1 \pm 19$ & $84.6 \pm 20$ & 0.881 \\
\hline $\begin{array}{l}\text { Başvuru kreatinin, } \\
\mathrm{mg} / \mathrm{dl}\end{array}$ & $1.26 \pm 0.5$ & $1.01 \pm 0.4$ & 0.003 \\
\hline Başvuru hematokrit, \% & $35.0 \pm 5.6$ & $37.8 \pm 4.9$ & 0.003 \\
\hline MPV & $8.48 \pm 1.76$ & $8.51 \pm 1.29$ & 0.090 \\
\hline NLR & $7.36 \pm 6.38$ & $5.45 \pm 7.52$ & 0.084 \\
\hline Kanama, n(\%) & $6(15)$ & $10(4)$ & 0.013 \\
\hline Girişimsel tedavi, $\mathrm{n}(\%)$ & $13(32)$ & $137(53)$ & 0.018 \\
\hline Ejeksiyon fraksiyonu, \% & $46.2 \pm 11.4$ & $48.2 \pm 11.5$ & 0.257 \\
\hline GRACE skoru & $161.15 \pm 32.8$ & $143.97 \pm 27.5$ & 0.003 \\
\hline \multicolumn{4}{|l|}{ GRACE RISK } \\
\hline Düşük, n(\%) & $0(0)$ & $25(10)$ & 0.033 \\
\hline Orta, $n(\%)$ & $13(32)$ & $104(40)$ & 0.380 \\
\hline Yüksek, n(\%) & $28(68)$ & $130(50)$ & 0.303 \\
\hline CRUSADE skoru & $42.20 \pm 14.8$ & $34.41 \pm 13.6$ & 0.001 \\
\hline \multicolumn{4}{|l|}{ CRUSADE RISK } \\
\hline Yok, $n(\%)$ & $3(7)$ & $33(13)$ & 0.020 \\
\hline Düşük, n(\%) & $6(15)$ & $78(30)$ & 0.321 \\
\hline Orta, $n(\%)$ & $13(32)$ & $55(21)$ & 0.124 \\
\hline Yüksek, n(\%) & $5(12)$ & $59(23)$ & 0.137 \\
\hline Çok yüksek, n(\%) & $14(34)$ & $34(13)$ & 0.040 \\
\hline MDRD(GFR), $\mathrm{ml} / \mathrm{dk}$ & $66.05 \pm 24.0$ & $77.60 \pm 22.7$ & 0.003 \\
\hline
\end{tabular}

Sayısal değişkenler ortalama \pm standart sapma olarak, kategorik değișkenler yüzdelik olarak verildi. CABG: Koroner arter bypass grefti, CRUSADE: Can rapid risk stratification unstable angina-Kararsiz anjina hastalarında hizlı risk sinıflandırması, GFR: Glomerular filtration rate, GRACE: Global Registry of Acute Coronary Events-Akut Koroner Olayların Global Kayıtları, KAH: Koroner arter hastalığı, MDRD: Modification of Renal Disease, MPV: Mean platelet volume, NLR: Neutrophil/lymphocyte ratio, PCI: Percutan coronary intervention

Çalışmamızda, mevcut veriler ve parametreler doğrultusunda 6. ay sonunda çok değişkenli lojistik regresyon analizi ile bazl mortalite öngördürücüleri saptandı. Bunlar; çok yüksek CRUSADE kanama riski [Odds oranı (OR): 1.911, güven aralığı (GA) \%95 (1.964 - 28.186), p= 0.030)], konservatif tedavi stratejisinin benimsenmesi [OR: 1.127, GA \%95 (0.131 0.799), $\mathrm{p}=0.014)]$ ve kardiyak biyobelirteçlerinin (troponin) pozitifliğiydi [OR: 1.837, GA \%95 (1.928 - 25.391), p= 0.030)] (Tablo III).

Tablo III: Çok değişkenli lojistik regresyon analizi ile mortalite öngördürücüleri

\begin{tabular}{|c|c|c|c|}
\hline & $\begin{array}{l}\text { Odds } \\
\text { oranı }\end{array}$ & \%95 CI & p değeri \\
\hline $\begin{array}{l}\text { Troponin } \\
\text { liği }\end{array}$ & 1.837 & $1.928-25.391$ & 0.030 \\
\hline $\begin{array}{l}\text { CRUSADE risk } \\
\text { (çok yüksek) }\end{array}$ & 1.911 & $1.964-28.186$ & 0.030 \\
\hline $\begin{array}{l}\text { Konservatif } \\
\text { tedavi }\end{array}$ & 1.127 & $0.131-0.799$ & 0.014 \\
\hline
\end{tabular}

\section{TARTIŞMA}

Çalışmamızda, 65 yaş ve üzeri popülasyonda konservatif tedavi ile 6 aylık mortalitenin girişimsel tedaviye göre daha fazla olduğu görülmüştür. Başka bir ifade ile yaşlı hastalar girişimsel tedaviden fayda görmüştür. $\mathrm{Bu}$ nedenle sağkalım yararı için yaşlı hastalarda daha fazla girişisel tedavi stratejisi benimsenmelidir.

Özellikle batı ve uzakdoğu toplumlarında yaş ortalamasının artmasına bağlı olarak AKS tanılı yaşlı hasta sayısında da artış görülmektedir. Genel nüfustaki yaş dağılımı ile ilişkilendirildiğinde ülkemizde de NSTEAKS ile 
başvuran hastalar içinde yaşlı hastalar oldukça geniş bir yer tutmaktadır7. Buna rağmen yaşlı hastalarda girișimsel tedavi halen yeterince yapılamamaktadır. Yaşlı hastaya uygulanacak tedaviye ilişkin alınan kararlarda; iskemi ve kanama riski, tahmini yaşam beklentisi, eșlik eden hastalıklar, yaşam kalitesi, hastanın istekleri, revaskülarizasyonun riskleri ve yararları göz önünde bulundurulmalıdır. AKS tanısı konduktan sonra hekim tarafindan risk/yarar ilişkisi değerlendirilirken, yaşlı hastalarda tedavi yan etkileri konusundaki çekinceler karar verme sürecini etkileyebilir. Yaşlı hastaların kliniği genelde daha kompleks olup komorbiditeleri daha fazla olmaktadır ${ }^{8}$. Bu hastalarda kardiyak rezervin azalmasının bir sonucu olarak enfarktüs boyutu daha belirgin olabilmekte ve bu da hemodinamik süreci etkileyebilmektedir ${ }^{9}$. Yaşlı hastalara girişimsel tanısal işlemlerin uygulanması, sonrasında revaskülarizasyon yapılması gereken riskli hastaların seçilmesi ve revaskülarizasyonun uygulanması ile belirgin bir prognostik düzelme sağlanabilmektedir. Ancak hekimlerin halen yaşlı popülasyonda girişimsel tedavi uygulamada tereddütlü oldukları bilinmektedir ${ }^{5,6}$.

Tamamı yaşlı popülasyonla yapılan, hastaların girişimsel ve konservatif tedavi grupları şeklinde mukayese edildiği büyük çalışmaların tatmin edici düzeyde olmaması nedeni ile tedavi yaklaşımı ile ilgili ortak bir fikir birliği oluşmamaktadır. Bir çalışmada NSTEAKS tanısı ile hastaneye yatırılmış 75 yaş ve üzeri hastalarda erken girişimsel tedavinin (72 saat içinde) konservatif tedaviye göre hastane içi mortalite, re-enfarktüs gelişimi ve tekrarlayan hastane yatışlarında herhangi bir üstünlük sağlamadığı görülmüştür. Sadece troponin yüksekliği olan hastalarda girişimsel tedavinin troponini normal olan hastalara göre primer sonlanım noktasında (ölüm, miyokart enfarktüsü, sakatlayıcı inme, 1 yıl içerisinde kardiyovasküler nedenler veya şidddetli kanama için tekrardan hastaneye yatış) azalma sağladığı görülmüştür ${ }^{10}$. FRISC-II çalış̧masında UAP ve NSTEMI tanılı hastalar girişimsel ve konservatif gruplara randomize edilmiştir. Girişimsel grupta, 6. aydaki ölüm ve MI görülme sıklı̆gı anlamlı olarak daha az görülmüştür $(\% 9,4$ vs. $\% 12,1)$. Altmış beș yaşın üzerindeki hastalar için girişimsel ve konservatif yöntemler karşılaştırıldığında, girişimsel tedavi ile 6. aydaki ölüm ve MI rölatif risk azalması \%34 olarak saptanmıştır ${ }^{11}$. Bauer T. ve arkadaşlarının 75 yaş ve üstü NSTEAKS tanılı hastaları kapsayan çalışmasında, konservatif tedavi verilen hastalarda girişimsel tedavi uygulanan hasta grubuna göre hastane içi mortalitenin ve ölümcül olmayan reenfarktüsün daha fazla olduğu görülmüştür. Aynı zamanda 1 yıllık mortalite de konservatif tedavi grubunda daha yüksek oranda saptanmıştır. Major kanama ise girişimsel tedavi grubunda daha sık görülmüştür ${ }^{12}$. Bizim çalışmamızda ise hastane içi ölüm oranları her iki grupta benzerdi (konservatif tedavi kolu $\% 4$, girişimsel tedavi \%2,6). Aynı şekilde major kanama görülme sıklıkları arasında fark yoktu (\%5 vs \%5). Altı aylık süreçte konservatif tedavi grubunda mortalite oranı, girişimsel tedavi grubuna göre anlamlı olarak daha fazla görüldü. Bach RG. ve arkadaşlarının yaptığı bir çalışmada 65 yaş ve üstü NSTEAKS tanılı hastalarda erken girişimsel tedavi ile 6 aylık mortalite veya enfaktüs oranında mutlak \%4,8, rölatif $\% 39$ azalma sağlandığı görülmüştür. Aynı çalışmada 75 ve üstü hastalarda erken girişimsel tedavinin yararının daha fazla olduğu tespit edilmiştir (mutlak azalma \%10,8, rölatif azalma \%56). Ancak major kanama oranı ise konservatif tedaviye göre daha fazla görülmüștür ${ }^{13}$. Bizim çalışmamızda da benzer olarak 6 aylık mortalite girişimsel tedavi grubunda daha az görülmüş ama farklı olarak major kanama oranları her iki grupta da benzer izlenmiştir.

Bir çalışmada NSTEMI tanısı ile girişim yapılmış hastalarda yüksek GRACE skoru ile koroner 
arter hastalığı ciddiyeti arasında pozitif ilișki görülmüştür ${ }^{14}$. Yine başka bir çalışmada AKS tanısı ile yatırılan 80 yaș ve üzeri hastalarda yüksek GRACE risk skoru, öncesinde anjiotensin dönüştürücü enzim inhibitörü/anjiotensin reseptör inhibitörü (ACEI/ARB) kullanımı ve başvuru anında düşük ejeksiyon fraksiyonunun hastane içi mortalite ile ilişkili olduğu görülmüştür. Aynı zamanda zirve troponin değerinin ölen hastalarda, yaşayan hastalara göre anlamlı olarak daha fazla olduğu tespit edilmiştir ${ }^{15}$. Bizim çalışmamızda da yaşayan hasta grubuna göre ölen hastalarda troponin değerinin ve GRACE risk skorunun daha fazla olduğu görülmüştür. Çalışmamızda girişimsel tedavi grubunun yaş ortalaması ile konservatif grubunun yaş ortalaması birbirine benzer olsa da yaş arttıkça girişimsel tedavi oranının düştüğünü görmekteyiz. Başvuru kreatinini düşük ve başvuru hematokriti yüksek olan hastalarda, girişimsel tedavi anlamlı olarak daha yüksek oranda tercih edilmiştir. Bunun sebebi, başvuru hematokriti ve GFR'si düşük hastalarda girișimsel tedavi sonrası meydana gelebilecek kanama ve/veya kontrast nefropatisi komplikasyonlarının öngörülmesi olabilir. Bundan dolayı konservatif tedavi stratejisi tercih edilmiştir. Çalışmamızda ölüm oranı, troponin pozitifliği olan hastalarda, negatif olan hastalara göre daha fazla görüldü. Ayrıca ölen hasta grubundaki troponin değeri, sağkalım grubuna göre daha yüksekti. Çalışmamız sonucunda troponin miktarı arttıkça, hastaların 6 aylık dönemde ölüm riskinin daha yüksek olduğu sonucuna varılabilir.

\section{SONUÇ}

Çalışmamı sonucunda yaşlı hasta popülasyonunda; çok yüksek CRUSADE kanama riskinin varlığl, troponin pozitifliği ve konservatif stratejinin benimsenmesi, 6 aylık mortalitenin bağımsız öngördürücüleri olarak belirlenmiştir. Çalışmamızda yaşlı hastalara detaylı bir klinik değerlendirme sonrasında girişimsel tedavi uygulandığında, yaş̧ı hastaların sağkalım açısından bu tedaviden fayda göreceği söylenebilir.

Limitasyonlar

Geniş hasta popülasyonlu prospektif çalışmalara göre hasta sayısının azlığı ve bu çalışmanın retrospektif oluşu, çalışmamızın kısıtlılığının en önemli sebebi olmaktadır. Yaş̧ı popülasyonda girişimsel tedavinin uzun dönem mortalite yararını belirlemeye yönelik geniş ölçekli çalışmalara ihtiyaç vardır.

Etik Kurul Kararı: Çalışmamız için gerekli onay, hastanemiz etik kurulu komisyonundan alındı (22/01/2014 tarih ve sayı no:96).

Çıkar Çatışması Beyanı: Çıkar çatışması bulunmamaktadır.

Finansal Destek: Bu çalışma herhangi bir fon tarafından desteklenmemiştir.

Declaration of Conflicting Interests: The author declare that she has no conflict of interest.

Financial Disclosure: No financial support was received.

\section{KAYNAKLAR}

1. WHO. (2013), World Health Organization, global health estimates 2013: deaths by cause, age, sex and regional grouping, 2000-2012, In: World Health Organization, Global health estimates Geneva, 08 Eylül 2015 , http://www.who.int/healthinfo/global_burden_dis ease/en

2. Mathers CD, Bernard C, Iburg KM, et al.Global Burden of Disease in 2002: data sources, methods and

[http://www.who.int/healthinfo/paper54.pdf].

GPE Discussion Paper No 54 Geneva, Switzerland:WHO; 2003, pp 1-118.

3. Dai X, Whitehead JB and Alexander KP. Acute coronary syndrome in the older adults, J Geriatr Cardiol. 2016 Feb; 13: 101-8. doi: 10.11909/j.issn.1671-5411.2016.02.012. 
4. Alexander KP, Newby LK, Cannon CP, et al. Acute coronary care in the elderly, part I: non-ST-segmentelevation acute coronary syndromes: a scientific statement for healthcare professionals from the American Heart Association Council on Clinical Cardiology: in collaboration with the Society of Geriatric Cardiology. Circulation 2007; 115: 25492569. doi: 10.1161/CIRCULATIONAHA.107.182615.

5. Brieger D, Eagle KA, Goodman SG, et al. GRACE Investigators. Acute coronary syndromes without chest pain, an underdiagnosed and undertreated high-risk group: insights from the Global Registry of Acute Coronary Events. Chest 2004; 126: 461- 469. doi: 10.1378/chest.126.2.461.

6. Patel MR, Chen AY, Peterson ED, et al. Prevalence,predictors, and outcomes of patients with non-STsegment elevationmyocardial infarction and insignifi - cant coronary artery disease: results from the the Can Rapid risk stratifi cation of Unstable angina patients Suppress ADverse outcomes with Early implementation of the ACC/AHA Guidelines (CRUSADE) initiative. Am Heart J 2006; 152: 607-10. DOI: 10.1016/j.ahj.2006.02.035.

7. Onat A, Karabulut A, Esen AM, ve ark.; TEKHARF çalışması, 2005 taramasına ilişkin mortalite ve koroner olay analizi, Türk Kardiyoloji Derneği Arş. 2006; 34: 149-53.

8. Kyriakides ZS, Kourouklis S, Kontaras K. Acute coronary syndromes in the elderly. Drugs Aging 2007; 24: 901-12. doi: 10.2165/00002512200724110-00003.

9. De Carlo M, Morici N, Savonitto S, et al. Sex-related outcomes in elderly patients presenting with nonST-segment elevation acute coronary syndrome: insights from the Italian Elderly ACS study. JACC
Cardiovasc Interv 2015; 8: 791-6. doi: 10.1016/j.jcin.2014.12.240.

10. Savonitto S, Cavallini C, Petronio AS, et al. Early Aggressive Versus Initially Conservative Treatment in Elderly Patients With Non-ST-Segment Elevation Acute Coronary Syndrome: A Randomized Controlled Trial, J Am Coll Cardiol Cardiovasc Interv. 2012 Sep, 5: 906-16. doi: 10.1016/j.jcin.2012.06.008.

11. Invasive compared with non-invasive treatment in unstable coronary-artery disease: FRISC II prospective randomised multicentre study. FRagmin and Fast 60 Revascularisation during In Stability in Coronary artery disease Investigators. Lancet 1999 Aug 28; 354: 708-15. PMID: 10475181.

12. Bauer T, Koeth O, Junger C, et al. Effect of an invasive strategy on in-hospital outcome in elderly patients with non-ST-elevation myocardial infarction. Eur Heart J 2007; 28: 2873-8. doi: 10.1093/eurheartj/ehm464.

13. Bach RG, Cannon CP, Weintraub WS, et al. The effect of routine, early invasive management on outcome for elderly patients with non-ST-segment elevation acute coronary syndromes. Ann Intern Med 2004; 141: 186-95. doi: 10.7326/0003-4819141-3-200408030-00007.

14. Öner E, Görgülü Ş, Aksu HÜ, et al. GRACE and TIMI scores in predicting the extension of coronary artery disease in patients with non-ST elevation myocardial infarction. Dicle Medical Journal, 2015; 42: 170-4 doi: 10.5798/diclemedj.0921.2015.02.0553.

15. Yılmaz S, Adalı MK, Kılıç O, et al. Predictors of inhospital mortality in very eldery patients presenting with acute coronary syndrome: A single-center study, Türk Kardiyol Dern Ars 2019; 47: 38-44 doi: 10.5543/tkda.2018.68792. 